\title{
Electrochemical Oxidation of Methionine Mediated by a Fullerene-C60 Modified Gold Electrode
}

\begin{abstract}
The usefulness of a C60-fullerene modified gold $(\mathrm{Au})$ electrode in mediating the oxidation of methionine in the presence of potassium ions electrolyte has been demonstrated. During cyclic voltammetry, an oxidation peak of methionine appearing at $\mathrm{b} 1.0 \mathrm{~V}$ vs. $\mathrm{Ag} / \mathrm{AgCl}$ was observed. The oxidation current of methionine is enhanced by about 2 times using a C60 modified gold electrode. The current enhancement is significantly dependent on $\mathrm{pH}$, temperature and C60 dosage. Calibration plot reveals linearity of up to $0.1 \mathrm{mM}$ with a current sensitivity of close to $50 \mathrm{~mA} \mathrm{~L}$ moll and detection limit of $8.2106 \mathrm{M}$. The variation of scan rate study shows that the system undergoes diffusion-controlled process. Diffusion coefficient and rate constant of methionine were determined using hydrodynamicmethod(rotating disk electrode) with values of $1.11105 \mathrm{~cm} 2 \mathrm{~s} 1$ and $0.0026 \mathrm{~cm}$ s1 respectively for unmodified electrode while the values of diffusion coefficient and rate constant of methionine using C60 modified Au electrode are $5.7106 \mathrm{~cm} 2 \mathrm{~s} 1$ and $0.0021 \mathrm{~cm}$ s1 respectively
\end{abstract}

Keyword: C60 modified Au electrode, Voltammetry, Methionine analysis, Electrocatalysis 